\title{
De família, Charque e Inquisição se fez a trajetória dos Pinto Martins (1749-1824)
}

Prof. Dr. Antonio Otaviano Vieira Junior ${ }^{\star}$

Resumo: Este trabalho apresenta as estratégias adotadas por quatro irmãos que saíram pobres de Portugal e fizeram fortuna no Brasil. Os Pinto Martins, filhos de um cavador de poços, construíram riquezas fundamentalmente a partir do comércio e da charqueada, apoiados num circuito comercial que envolvia as capitanias de Pernambuco, Rio Grande do Norte, Ceará e Rio Grande do Sul. Durante toda a segunda metade do século XVIII e as primeiras décadas do XIX, esses irmãos traçaram uma história de enriquecimento fundada nas relações de parentesco, nas alianças e compromissos mútuos. A família foi base de sustentação para que eles se efetivassem como homens bons, detentores de patentes militares, contratos reais e membros leigos do Tribunal do Santo Ofício de Lisboa.

Palavras-chave: Charqueadas. Inquisição. Ceará. Rio Grande do Sul. Elite.

Nos últimos anos, a historiografia brasileira foi tomada por uma instigante querela sobre o período colonial. De um lado, os defensores da produção do Antigo Regime tupiniquim, questionando a ideia de centralidade político-administrativa na metrópole; do outro, o esforço de consolidar a imagem da América

\footnotetext{
* Professor da Faculdade de História da Universidade Federal do Pará (UFPA), Pesquisador do Conselho Nacional de Desenvolvimento Científico e Tecnológico (CNPq). Endereço eletrônico: otaviano@ufpa.br.
} 
portuguesa a partir das demandas da Coroa, marcadamente reconhecendo a presença do Estado português no processo de colonização e administração de suas possessões no Ultramar (FRAGOSO et al., 2001; FRAGOSO et al., 2006; MELLO, 2006). No escopo dessa discussão, menos importante é acatar qualquer construção de leis aplicada à explicação do Brasil colonial. Entretanto, devese considerar seus desdobramentos, principalmente no que diz respeito à necessidade de repensar a América portuguesa, com especial atenção à trajetória da formação de elites locais. ${ }^{1}$

Nesse sentido, merece destaque a necessidade de análises que extrapolem as capitanias centrais e ponderem sobre outras realidades. Considerando a formação de grupos de elite para além do açúcar, da mineração ou das instâncias administrativas da capital da colônia. $\mathrm{O}$ estudo de trajetórias individuais em áreas de economias periféricas pode trazer novos elementos para destacar múltiplas possibilidades de formação e consolidação de elites locais: eis o esforço deste ensaio.

\section{Em Pelotas}

Ao longo do final do século XVIII e no avançar do XIX, o Rio Grande do Sul conheceu um significativo crescimento econômico, baseado na produção do charque. A maior quantidade de oficinas de carne estava em Pelotas, com aproximadamente 15 estabelecimentos saladeiris (GUTIERREZ, 1993, p. 116). Dentre os maiores proprietários e fundadores das oficinas da região, encontrava-se José Pinto Martins, um dos quatro irmãos que partiu de Meixomil, no norte de Portugal, e ancorou em Recife. Embora tenha nascido pobre e no outro lado do Atlântico, José fez fortuna entre Recife, Aracati (no Ceará) e Pelotas. Nessa última vila, veio a falecer, não sem deixar uma invejável fortuna e uma intrigante trajetória de vida.

No mês de maio de 1824, numa casa no arroio de Pelotas, entre Boa Vista e o canal de São Gonçalo, José Pinto Martins fez seu testamento. Como na maioria desses documentos, entre as linhas ditadas, surgia a preocupação de controlar a divisão do 
patrimônio material que acumulou ao longo da vida e o esforço de assegurar à família a maior parte da herança. ${ }^{2}$ Embora o testamento, num primeiro olhar, não apresente especificidades, em uma leitura mais paciente, remete-nos a uma trama, urdida a partir do montante, da qualidade dos bens e da relação com os herdeiros.

Associar o testamento de José Pinto Martins a outras fontes de pesquisa, como as habilitações dos Familiares do Santo Ofício, coloca-nos numa apagada trilha do tempo e nos remete às estratégias individuais de construção de riquezas e capital simbólico. Entre Portugal e várias capitanias brasileiras, o século XVIII se apresenta como cenário para a inserção dos irmãos Pinto Martins no rol dos homens bons.

Embora o sul do Brasil já produzisse carne salgada desde o século XVII, José Pinto Martins é considerado pela historiografia gaúcha como um dos fundadores das charqueadas na região. Seu suposto pioneirismo está atrelado ao grande volume de charque produzido em sua oficina (CROSSETTI, 1999, p. 166-173). A fazenda onde morava, localizada no arroio de Pelotas, formava um complexo de edificações: a casa principal, residência de José e de familiares (que incluía o irmão Antonio e alguns filhos legítimos), ganhava destaque logo no primeiro olhar. O material empregado na edificação era caro e garantia um refinamento acessível a poucos proprietários da região. Era uma casa de pedra e cal, com largas paredes e coberta de telha. Além de possuir sala, quartos e varanda, tinha porta e janelas de vidro. Dentro, a mobília não era escassa, como o costume à época. O móvel que ganhava mais destaque era a cama de madeira, com suas gavetas, colchão de palha, travesseiro de marroquim e cortinado. No mais, ainda existia uma cômoda grande de jacarandá, mesas com suas respectivas cadeiras, incluindo uma redonda com abas, e baús que guardavam roupas, documentos e segredos. ${ }^{3}$

A casa e a mobília fortalecem a imagem de um abastado proprietário. Além da casa principal, integrava o complexo de suas edificações várias outras construções. Um armazém de tijolo e telha, destinado aos atanados. A casa de graxeira, onde se fabricava graxa, que era um tipo de cera produzida a partir da gordura do boi e utilizada para tratar o couro. Esta última construção era 
bem equipada, incluindo balanças, tacho de cobre e caldeiras de ferro para ferver a gordura, barris para armazenar a graxa e deixar a carne na salmoura, pilão de socar sebo e outros apetrechos. Para a proteção e secagem do sal, importantíssimo na produção do charque, José havia mandado construir uma casa exclusivamente para este fim, cujas paredes eram de tijolo e a cobertura de telhas. Havia ainda um galpão coberto de palha, para abrigar o gado em fase de abate. Para seus escravos, que eram mais de 30, erguera uma senzala de tijolo e telha. Assim, quando o visitante mais desavisado avistava suas propriedades, logo poderia se impressionar com as muitas construções, com um movimento intenso de escravos, correndo, transportando gado vivo, gado morto, carcaças, sebo, barris de graxa etc. E essa espécie de complexo do charque era, para José Pinto Martins, fonte maior de riqueza e uma possível tentativa de apagar a origem pobre de sua família.

\section{A Família}

José morou em diferentes capitanias antes de fixar residência e explorar a pecuária em Pelotas. Em Pernambuco, sua casa era em Recife, importante porto de venda de charque e couro e de entrada de produtos vindos da Europa. No Ceará, foi morador de Aracati, vila que se destacou na produção de charque e como veio comercial para entrada de produtos no Sertão (VIEIRA Jr., 2004, p. 61-66).

A base produtiva da vila cearense não só influenciou a dinâmica econômica, mas também deixou marcas profundas no cotidiano dos moradores. O cenário urbano era matizado por ossos nas portas das residências, ${ }^{4}$ por um grande número de oficinas, pelos quintais com mantas de carne sobre estacas e expostas ao sol, pelo cheiro forte de carne e couro que impregnava o dia e a noite dos moradores e pela quantidade de moscas que vinham, atraídas pelas sobras de carne e vísceras, e acabavam invadindo as moradas, as lojas e até mesmo as missas: 
(...) porquanto hera bem notório que a matansa dos gados nas sobreditas officinas dentro da vila geravão todos os anos hum pestilento, fétido, e imundícias... e de incômodos, os quaes athe se estendião a impedir a decência com que se devia selebrar o Sacro Santo Sacrifício da Missa que por mais cautelas que hajão em estar o acolito continuamente abanando as moscas, e levantar o Sacerdote o Sagrado Calix cuberto contra o Rito Romano, sempre nelle cahem as moscas e as Imagens e Ornamentos da Igreja sempre estão sórdidos, e indecentes pela mesma cauza.... (Auto de segunda Audiencia geral que requereo a Câmara nesta Vila de Aracati [1780], apud NOBRE, 1977, p. 94).

Mesmo com inconvenientes causados pelo criatório e pelo charque, a empreitada pecuarista significou a base da ocupação e da economia do Sertão do Ceará. Embora a produção açucareira tenha dado um impulso inicial para a expansão do criatório de gado, a pecuária cresceu em importância dentro da economia brasileira justamente na contração da exportação do açúcar. A rentabilidade do plantio da cana começou a decair a partir da segunda metade do século XVII e da primeira do XVIII. Esse fato foi engendrado pela conjuntura externa, desfavorável ao preço do açúcar, como também pelo fortalecimento da atividade mineradora, que era mais atraente para o investimento de capital. A pecuária se beneficiava dos capitais menores e tinha sua expansão acentuada e os atanados produzidos no Nordeste ganhavam crescente fatia do mercado externo. Esse comércio atlântico começou a definhar em fins do século XVIII ( RIBEIRO Jr., 1976, p. 145).

Nesse contexto, os Pinto Martins, que tinham lojas, barcos e oficinas em Aracati, usufruíram do desenvolvimento da exportação pecuarista durante toda a segunda metade dos Setecentos e fizeram fortuna com um sistema que envolvia o fluxo de mercadorias pelo Sertão cearense, a produção e a exportação do charque e do couro para Recife. 
De família, charque e Inquisição se fez a trajetória...

A partir desse comércio, José Pinto Martins e seus irmãos construíram significativo cabedal e deram início a uma empreitada para que a família pudesse ocupar novo lugar social; esse esforço conjugou acumulação de patrimônio material e manipulação de títulos, patentes, mercês e cargos. Empenhados em pertencerem ao corpo leigo habilitado pela Inquisição e atestarem uma suposta limpeza de sangue, os quatros irmãos solicitaram ao Conselho Geral do Tribunal do Santo Ofício a nomeação como Familiares. Pedido compreendido à luz do comportamento considerado geral das elites sociais no Brasil, que procuravam alcançar signos de distinção social definidos pelo centro do Império. Por isso, o estatuto de pureza de sangue passava a ser arma nas lutas pelo poder de classificar os individuos esgrimidas no campo da genealogia (MONTEIRO, 2003, p. 135). Isso nos faz entender parte da trajetória dos Pinto Martins dentro de um contexto específico de promoção social e a importância de signos genealógicos nesse cenário.

Em setembro de 1787, após ter investigadas sua genealogia e "moral" em Portugal, Pernambuco e Ceará, José Pinto Martins conseguiu a aprovação de seu nome como Familiar da Inquisição. No parecer final do Comissário do Santo Ofício que confirmou sua habilitação, lemos:

He o habilitando pessoa de bom procedimento; Vida, e Costumes Capas de Ser encarregado de Negócios de Supozicao e Segredo, e de servir ao Santo Ofício no Cargo de Familiar; tratandose com Limpeza e aceio, e de seus Negócios tira Lucros para se tratar, sabe ler, escrever, e representa ter perto de trinta annos de idade... (Direção Geral de Arquivos/Torre do Tombo (DGARQ/TT), Habilitação de Familiares, maço157, doc. 3031)

Como dito anteriormente, a busca pela nomeação para o posto de Familiar do Santo Ofício não era coisa sem importância. Muitas famílias viam na habilitação uma possibilidade de consolidar hegemonias políticas e econômicas. Alguns casos podem revelar um rápido processo de enriquecimento, a construção de 
uma elite local com ramificações em diferentes capitanias, a montagem de uma imbricada rede que envolvia membros de uma mesma família e estratégias de fortalecimento político (WADSWORTH, 2004; TORRES, 1994; CALAINHO, 2006).

Ainda em Portugal, os antepassados dos Pinto Martins enfrentaram significativo processo de empobrecimento. Construindo uma história tecida no norte lusitano, no início do século XVIII, e marcada por atividades agrícolas, pela venda de serviços, por construções de pequenas tabernas e por viagens ao Brasil. ${ }^{5}$ Assim, as falas das testemunhas da habilitação revelam disparidades na trajetória familiar entre a metrópole e a colônia, entre pobrezas e riquezas, entre os servos da terra e ricos comerciantes, entre a agricultura e o comércio.

Iniciemos com os bisavôs, avôs e pais de José e de seus outros três irmãos. O objetivo é compreendermos esse grupo, na sua origem em Portugal e na sua efetivação no Brasil, lugares onde a investigação dos antepassados era um elemento fundamental de hierarquização na escala social (MELLO, 2000). A primeira referência nos remete mais especificamente à freguesia de Freamunde, então Bispado de Penafiel. Uma vila pequena, que não se impunha pelo desenvolvimento de suas estruturas urbanas, mas por uma dispersa população vivendo em casas isoladas e abertas para quintais cobertos por plantações de milho e de vinha. ${ }^{6}$ Além da agricultura, no geral, outra atividade ganhava destaque: o pastoreio. Nas residências mais isoladas, a vida se arrastava, e as famílias reunidas se fortaleciam em dietas enriquecidas por gordura animal e por goles de cerveja e cidra. ${ }^{7}$ Lá moravam Manoel Martins e Maria Coelha, bisavôs maternos de José, um casal pobre que vivia da lavoura. Tiveram dois filhos. Um chamava-se Agostinho Martins, e o outro, que nos interessa mais prontamente, era Antonio Martins (avô de José).

Logo Antonio Martins deixou as terras onde nascera e foi morar em Meixomil, também freguesia de Penafiel. Lá casou com Maria Ferreira e passou a sobreviver da taberna que possuía. Pois bem, o casal Antonio e Maria teve um menino e uma menina. $\mathrm{O}$ filho chamava-se, como o pai, Antonio Martins, que continuou morando na região e vivia de fazer e concertar tamancos - um 
ofício pouco digno numa sociedade onde o trabalho manual era considerado atividade não condizente com a nobreza.

A menina, e é esta que nos interessa mais de perto, ganhou o nome de Catarina Martins - mãe de José. Casou-se com João Pinto (pai de José). Era ele homem pouco instruído, que deixara suas terras de origem na freguesia de Santa Eulália de Passos para morar em Meixomil. Lá viveu das jornadas de seu trabalho que exercia como cavador de poços ou, atendendo os termos da época, como mineiro d'agua.

A família de João Pinto vinha em franco processo de pauperização: seus pais eram agricultores e foram obrigados a vender a terra. Na documentação, não fica claro o motivo da venda, mas é exposta pelas testemunhas sua consequência: acabaram como caseiros da propriedade que possuíam, ou seja, passaram da posição de pequenos proprietários para a de empregados. ${ }^{8}$ Os detalhes referentes à família paterna de José Pinto Martins são menos precisos do que os do lado materno, no entanto, as testemunhas também destacam a origem pobre de seu pai e avós.

Do casamento de João Pinto e Catarina Martins, nasceram quatro filhos: João, Bernardo, Antonio e o nosso José Pinto Martins. Todos pisaram e trabalharam no Sertão do Ceará. O primeiro deles foi João Pinto Martins, que deixara Meixomil com 10 anos de idade. Fora criado por Domingos Pinto Lobo, homem solteiro que o embarcara. Ao chegar ao Brasil, não encontrou parentes para recebê-lo e foi obrigado a aprender sozinho a lidar com o novo mundo. Assim, começou em terras brasileiras a saga dos Pinto Martins que, de netos de taberneiros e caseiros ou filhos de jornaleiro, passaram ao patamar de ricos comerciantes e Familiares do Santo Ofício.

\section{A Inquisição}

José Pinto Martins, um dos quatro irmãos, no dia 24 de janeiro de 1787, deu entrada, junto ao Tribunal do Santo Ofício, ao pedido de nomeação como Familiar. Nessa época, residia entre 
Recife e Aracati, sendo já definido por alguns dos seus contemporâneos como homem que trata de negocio de fazenda para o Sertam, do qual percebe avultados lucros e possue cabedal. ${ }^{9} \mathrm{~A}$ base do comércio entre localidades em que José residia era simples: de Recife, partiam embarcações com mercadorias em geral; tais produtos eram vendidos ou trocados em Aracati, onde sumacas chegavam a transportar cerca de 80 toneladas de charque por viagem, carne esta que seria consumida ou exportada a partir de Recife. Entre os dois portos, os Pinto Martins faziam fortuna. ${ }^{10}$

O pedido para a nomeação como Familiar do Santo Oficio era passo importante, trilhado por tantos outros comerciantes, incluindo os três irmãos de José. E se efetivava como forma de promoção social, principalmente utilizada por membros de uma elite comercial lusitana, o que na prática justificaria, na segunda metade do século XVIII, o aumento significativo de habilitações de Familiares na Inquisição de Lisboa, embora houvesse uma diminuição - também significativa - do número de réus condenados (TORRES, 1994, p. 123).

O perfil dos candidatos a Familiares do Santo Ofício no Brasil durante a segunda metade do século XVIII era, em geral, de comerciantes que originalmente pertenciam a segmentos sociais com poucos recursos e que posteriormente acumularam fortuna em terras brasileiras. Como tantos outros, os Pinto Martins também se enquadravam nesse perfil. José tinha mais três irmãos, todos portugueses e de origem pobre: Antonio, João e Bernardo. Antonio Pinto Martins solicitou sua habilitação como Familiar no mesmo dia que José, ou seja, no dia 24 de janeiro de 1787 . João entrou com seu pedido de habilitação no dia 01 de fevereiro de 1774, ou seja, 13 anos antes de José e Antonio. Bernardo registrou sua habilitação em 11 de abril de 1781. A precocidade do pedido de João, quando comparado aos outros irmãos, talvez se explique pelo fato de ser o irmão mais velho e ter chegado a Recife ainda muito jovem, com pouco mais de dez anos de idade. ${ }^{11}$

O fato de quatro irmãos, originalmente com parcos recursos econômicos e posteriormente envolvidos no comércio, candidatarem-se ao mesmo posto inquisitorial nos faz pensar nas vantagens relacionadas a essa nomeação - principalmente quando 
De família, charque e Inquisição se fez a trajetória...

consideramos o espaço temporal de 13 anos entre o pedido de nomeação do irmão mais velho até a solicitação de José Pinto Martins. Entretanto, antes de analisar melhor a estratégia adotada pelos Pinto Martins, vejamos o que era ser um Familiar do Santo Ofício.

\section{Familiar}

Quando saiu o parecer favorável à habilitação de José Pinto Martins, e do seu irmão Antonio, em 1787, as diretrizes de atuação da Inquisição portuguesa estavam sob a tutela do último Regimento do Santo Oficio da Inquisição dos Reinos de Portugal, ordenado pelo cardeal Da Cunha - editada em 1774. Esse regimento foi precedido por outros três: os de 1552, 1613 e 1640 (ASSUNÇẪO e FRANCO, 2004, p. 107-418). Sendo corpo legislativo, estava dividido entre artigos e parágrafos, procurando enquadrar as ações inquisitoriais lusitanas aos ditames pombalinos. A política de Sebastião José de Carvalho e Melo aproximou a Inquisição do poder régio e buscou diminuir as ingerências papais (CALAINHO, 1992, p. 44).

A rede de Familiares começou a ser construída em Portugal no final do século XVI, com a ordem do Inquisidor Geral cardeal D. Henrique, mas a montagem dessa estrutura foi lenta. Em 1608, o Tribunal de Évora contava apenas com sete Familiares. Em 1692, o Conselho Geral da Inquisição de Portugal determinou número de vagas para a nomeação de Familiares nos seus tribunais: 178 para Évora, 236 para Coimbra e 187 para Lisboa (BETHENCOURT, 1994, p.50).

A Inquisição lusitana, diferentemente de sua irmã Ibérica, aumentou intensamente o número de Familiares ao longo do século XVIII, chegando a 2.252 Familiares somente entre 17611770. Durante toda a existência da Inquisição portuguesa (15361821), foram pedidas aproximadamente 20.000 habilitações (TORRES, 1994, p.127). No Brasil, existe uma divergência nos dados relacionados ao número de Familiares nomeados (SIQUEIRA, 1978, p. 181). Os casos dos Pinto Martins, cujas habi- 
litações ocorreram na segunda metade do século XVIII, estavam em sintonia com a maioria das habilitações que encontramos para o Ceará nesse período, ou seja, era notadamente marcada a demanda de habilitações solicitadas por membros de uma elite comercial local (VIEIRA Jr., 2008, p. 123).

Os Familiares não eram nem funcionários e menos ainda auxiliares, eram uma espécie de milícia voluntária à disposição do Santo Ofício (HIGGS, 1992, p.374-376). A obrigação fundamental do Familiar era denunciar pessoalmente ou por carta aos inquisidores qualquer "caso que lhes pareça ofensivo da nossa santa fé, ou se os penitenciados não cumprirem suas penitência". ${ }^{12}$ Além disso, poderiam ser encarregados de diligências pelos Comissários, para efetuarem prisões ou verificarem denúncias; nessas empreitadas, deveriam vestir o Hábito de Familiar. Na véspera da comemoração de São Pedro Mártir, patrono da Inquisição, os Familiares deveriam aparecer nas Igrejas de suas paróquias para acompanharem o Tribunal e assistirem à festa em homenagem ao santo. $^{13}$

$\mathrm{Na}$ prática, eram espiões que tinham a competência potencializada não em ações concretas, mas no clima de vigilância que era criado a partir de suas nomeações. Ganhavam destaque também por poderem ser leigos e indicarem uma aproximação entre o poder temporal e o religioso (SIQUEIRA, 1978, p. 172). Esse grupo assegurava a presença viva da Inquisição, principalmente a partir de suas ações policiais e investigativas. Representavam uma ponte entre o réu e o Tribunal, tendo um papel de destaque na América Portuguesa: auxiliar a depuração da fé a partir das imposições contrarreformistas do Concílio de Trento e no combate específico das religiosidades gestadas nas interfaces culturais que envolviam as populações no Brasil (CALAINHO, 2006a, p. 7273).

As Visitações do Santo Ofício ocorridas na Bahia, em Pernambuco, no Grão-Pará e Maranhão, aliadas às Devassas ou Visitas Pastorais, montavam uma imbricada rede de controle. Essa trama se fortaleceu na América lusitana entre os séculos XVII e XVIII, com a intensificação das nomeações de Familiares, que vigiavam cotidianos de diferentes rincões e criavam suporte para 
De família, charque e Inquisição se fez a trajetória...

a efetivação das Visitas e Devassas (CALAINHO, 2006a, p. 6061). Nesse movimento, o século XVIII teve um papel especial, principalmente por assistir a um aumento significativo de nomeações de Familiares, articuladas com a multiplicação de dioceses e prelazias, com a regulamentação das visitas pastorais e com o plano maior de fortalecimento da estrutura eclesiástica no Brasil (CALAINHO, 2006b, p. 91).

A habilitação de José Pinto Martins e de seus irmãos se enquadrava na forte tendência da Inquisição lusitana de ter ampliado seu quadro de Familiares. A historiadora Daniela Calainho escreveu um dos primeiros trabalhos no Brasil dedicados ao estudo exclusivo dos Familiares da Inquisição na América portuguesa (CALAINHO, 1992). A autora fez um exaustivo levantamento dos Familiares habilitados no Brasil. O período que apresentou maior número de habilitação foi o século XVIII, com 90\% do total de Familiares. Ainda segundo Calainho, 76\% dos habilitados estavam associados diretamente a atividades comerciais. A própria autora reconhece limites de seu levantamento, pois seu banco de dados nos informa 1.708 nomes de Familiares para o Brasil entre os séculos XVII-XIX; número menor do que os 3.114 nomes levantados por outro pesquisador: Veiga Torres (CALAINHO, 2006a, p.79; TORRES, 1994, p. 134).

Apesar da diferença entre os números de Familiares analisados, existe uma aproximação entre as análises de Calainho e de Veiga Torres. Este autor corrobora tanto a ideia do aumento significativo de habilitados no século XVIII, como também destaca a presença marcante de comerciantes: entre 1721-1770, 34\% dos Familiares eram comerciantes e, entre 1770-1821, o número subiu para 42\% (TORRES, 1994, p. 134).

Todos esses números e percentuais correm no sentido de pontuar o lugar social das habilitações de José Pinto Martins e de seus irmãos. Ou seja, comerciantes portugueses de origem pobre se habilitando como Familiares no século XVIII no Brasil era uma imagem comum. Mas, se o era para América lusitana em geral, seria para o Ceará?

A própria identificação da habilitação de José e de seus irmãos, todos com moradas no Ceará, já é um dado significativo. 
O número de Familiares cearenses identificados por Calainho era de dois. Aqui surge um problema, fruto da própria dinâmica econômica cearense, das atividades dos habilitados e da importância periférica da capitania do Ceará.

No levantamento preliminar que fizemos, circunscrito apenas à segunda metade do século XVIII e início do XIX, encontramos 20 nomes de habilitandos que tinham moradas cearenses. Em geral, esses Familiares deslocavam-se regularmente para localidades pernambucanas. Dos 20 habilitados, 10 se declararam ou foram declarados como envolvidos no comércio. $\mathrm{O}$ esforço de declarar Recife como residência pode ser explicado pela importância econômica e política da cidade; principalmente se considerarmos que o Ceará até 1799 era capitania anexa de Pernambuco. Morar na sede administrativa poderia ser uma maneira de valorizar o lugar social do candidato. Em geral, nesse período, a capitania do Ceará era considerada Sertão: ou seja, distante, ermo e com dificuldades para colonização (ARAÚJO, 2000; VAINFAS, 2000, p. 528-529).

Um dos irmãos de José Pinto Martins, no caso Bernardo Pinto Martins, evidencia a intensidade dos deslocamentos. Bernardo era comerciante, contratador real e de gado ao vento de Russas no Ceará, juntamente com seu irmão João, entre os 178288. No seu processo de habilitação, declarou morar em Recife. O próprio José tinha residência confusa. Algumas testemunhas disseram que ele morava em Recife, outras em Aracati. No seu processo, um dos inquiridos, o padre Manoel Felipe Gonçalves, chegou a afirmar que José residia ora em Recife, ora em Aracaty. O outro irmão, Antonio, também teve sua residência dividida, no caso entre Recife e Mossoró. João, o irmão mais velho, era rico comerciante em Recife, mas possuía morada, oficina de charque, estaleiro e uma das principais lógeas ${ }^{14}$ em Aracati, onde passava boa parte do ano.

Embora todos fizessem fortunas no Sertão do Ceará, suas residências dividiam-se entre diferentes vilas, incluindo Aracati, e suas moradas declaradas estavam associadas diretamente à vila econômica e politicamente mais importante: Recife. O porto da capital pernambucana era um importante ponto de ligação 
comercial, principalmente com a metrópole e amparava uma significativa elite administrativa com laços diretos com a Coroa. E mais um dado deve ser considerado para entendermos esses deslocamentos: as oficinas de charque e o comércio do produto não aconteciam em Aracati durante todo o ano: negocio este que sete, oyto mezes no anno fazo o dito Lugar [Aracati] parresser hua Prassa populosa. ${ }^{15}$ Nesse ir e vir, não fica impossível imaginarmos os deslocamentos de parte dos comerciantes locais, inclusive para Recife.

Em resumo, habilitar comerciantes na segunda metade do século XVIII era tendência geral adotada pelo Santo Ofício. E os Pinto Martins não representavam exceções. A dificuldade de associá-los ao Ceará estava justamente no ofício, que os obrigava ao constante deslocamento e à efetivação de moradas em vilas e capitanias diferentes.

\section{A Habilitação}

A habilitação como Familiar incluía a análise da genealogia do candidato, desde bisavôs, para descobrir se havia na história da família raça alguma de judeu, cristão-novo, mouro, mulato, negro ou mourisco ou descendente de outra infecta nação... ${ }^{16}$ Além disso, era investigado se o candidato vivia descentemente, ou seja, se tinha um cabedal significativo, se sabia ler e escrever, se não tinha algum parente punido pela Inquisição ou acusado do crime de lesa-majestade e se não era pai de filho ilegítimo. Caso o candidato fosse casado, a investigação também se aplicava à esposa e sua família. A Inquisição utilizava investigadores, às custas do processo, em todos os locais de origem e de morada do candidato e das suas gerações passadas. Nesses lugares, testemunhas eram convocadas e respondiam às perguntas dos inquisidores acerca do passado da família e do próprio candidato.

Para as habilitações dos Pinto Martins, podemos considerar alguns elementos a partir da nomeação e inquirição das testemunhas: em geral, eram escolhidas pelos representantes do Santo Ofício, entre aquelas que conviveram com o candidato ou com seus familiares e tinham boa fama pública. No caso de José e 
Antonio Pinto Martins, existe um forte indício de que suas habilitações correram juntas: primeiro, foram enviadas na mesma data, com a letra do mesmo escrivão, e foram convocadas no Brasil as mesmas testemunhas.

Os depoentes inicialmente demonstravam surpresa, o que não significava necessariamente sinceridade, por serem convocados. Com a mão direita sobre a Bíblia, faziam o juramente de verdade e começavam a responder as perguntas dos inquisidores sobre o habilitando e sua família. Mas, antes de expor seu conhecimento e opinião acerca do candidato, as testemunhas informavam suas idades, ocupações, lugar de nascimento e de morada, patentes militares e se eram Familiares. Esse primeiro momento do inquérito servia para legitimar e marcar o lugar social do inquirido e também, do próprio habilitando.

Na habilitação de José Pinto Martins, a caracterização social das testemunhas, numa comparação entre Portugal e Brasil, pode revelar mudança no grupo de sociabilidade da sua família. Em Meixomil, foram inquiridas cinco testemunhas, três lavradores, um jornaleiro e outra que não declarou a ocupação. Em Recife, foi ouvido o mesmo número de depoimentos, dentre os quais quatro eram comerciantes e um era padre na vila cearense de Icó.

Ou seja, as inquirições em Portugal ficaram circunscritas ao grupo de convívio da família de José, principalmente por ter ele vindo ao Brasil ainda novo. A família não travava relações diretas com comerciantes ou, se travava, não era o grupo principal de sociabilidade. Não nos esqueçamos de que a sociedade lusitana era estamentária, em que os estamentos se comunicavam, mas não estabeleciam relação cotidiana que não fosse tramada por hierarquias legitimadas por conceitos como nobreza e privilégios, com dominio da politica sobre a economia. ${ }^{17}$

Aqui no Brasil, onde José construiu fortuna com o comércio, o grupo privilegiado como testemunha foi justamente o de negociantes, o que pode ser indicativo da montagem de uma rede entre negociantes, alguns nascidos em Portugal, que se apoiavam mutuamente - inclusive durante o processo de habilitação. Essas testemunhas eram importantes, porque atestavam a limpeza do sangue do candidato e legitimavam sua pretensão ao cargo de Familiar. 
De família, charque e Inquisição se fez a trajetória...

No caso do irmão mais velho, João Pinto Martins, num processo que ocorreu 13 anos antes da habilitação de José, as testemunhas apresentaram origem social semelhante. Nesse caso, foram ouvidas em Portugal 35 testemunhas e, destas, 12 eram lavradores; 13 eram mulheres e, por isso, não aparecem suas ocupações; um era jornaleiro; outro era tamanqueiro; três eram padres; um alferes e cinco não tiveram o ofício declarado ou o mesmo era ilegível. No geral, as testemunhas se enquadravam em estamentos sociais distantes da nobreza e das atividades comerciais ou militares (salvo o único alferes). Já em Recife foram ouvidas seis testemunhas, das quais quatro eram Familiares e comerciantes, um era padre e o outro licenciado. João Pinto Martins tinha mudado de grupo de convívio, demonstrando apoio de membros de uma elite local, comercial e que tinha a legitimidade associada ao Santo Ofício.

O mesmo João Pinto Martins, depois de habilitado, foi convocado como testemunha de outro processo de habilitação envolvendo moradores do Ceará. O candidato em questão residia em Aracati: era Pedro da Costa Barros. Pedro era genro de Souza Braga, e ambos se impunham, ao lado do próprio João, como os mais abastados comerciantes da região. Em 1778, João Pinto Martins depunha de maneira favorável sobre as qualidades e a limpeza de sangue de Pedro Costa Barros. No caso de Pedro, todas as seis testemunhas eram comerciantes e habilitados pelo Tribunal da Inquisição. As testemunhas que depuseram no processo de Pedro revelaram nitidamente a ajuda mútua entre comerciantes que operavam na mesma localidade e que potencialmente seriam concorrentes. Apoio que poderia ser pontual, mas que beneficiara anteriormente João Pinto Martins e que posteriormente beneficiaria seus irmãos - incluindo José.

\section{Irmãos em Pares}

Outro ponto pode ser destacado a partir da análise das habilitações de José Pinto Martins e de seus irmãos, e que em parte ajuda a explicar como um filho de jornaleiro de Portugal se trans- 
formou em rico comerciante no Ceará, Pernambuco e Rio Grande do Sul. Esse destaque deve ser dado para a montagem de estratégias que envolviam a articulação e apoio mútuo entre os irmãos. E mais, eles agiam em duplas, articuladas principalmente a partir da geração: os dois irmãos mais velhos, João e Bernardo, formavam um grupo, e os dois mais novos, José e Antonio, integravam o outro. João nasceu em 1739, Bernardo provavelmente em 1752, José em 1755 e Antonio em 1762 - a diferença de idade entre o mais velho e o mais novo era de 23 anos. As duas duplas não se isolavam e se articulavam entre si.

João foi o primeiro a chegar à América portuguesa. Chegou com parcos recursos em Recife. Ainda segundo algumas testemunhas, João havia deixado Portugal com 10 anos de idade, ou seja, em 1749. Sua habilitação era de 1774, o que significa que, em 25 anos, conseguiu fazer fortuna no Brasil. Segundo Oliveira:

Em 1765, João Pinto Martins recebeu do Capitão-Mor da capitania a patente de Capitão de Ordenanças dos Homens Forasteiros na vila de Santa Cruz do Aracati (...) em 1775 aforou quatro braças de terras no Senado da Câmara, nas quais possuía duas casas de morada na rua de Santo Antônio, a parte mais importante da vila, onde se localizavam as lojas de fazendas. (OLIVEIRA, 2006, p. 12)

Em Recife, João Pinto Martins casou-se. De imediato, ganhou uma cunhada que era esposa de Familiar do Santo Ofício, ou seja, inseria a família num grupo relativamente pequeno dos limpos de sangue, do qual João passou a fazer parte. Esse Familiar chamava-se João Coelho Bastos; era importante charqueador em Aracati e sócio de João Pinto Martins. Utilizando sua entrada na família da esposa, o mesmo João ganhou um parceiro comercial, que mantinha sociedade na propriedade de barcos e no comércio com o Sertão. Assim, com o casamento, João Pinto Martins não apenas ganhou uma cunhada habilitada, pois era casada com um Familiar, como também usufruiu da sociedade comercial com o concunhado. Não podemos especular se esse foi o início da fortuna do mais velho dos Pinto Martins, mas essa aliança matrimonial 
De família, charque e Inquisição se fez a trajetória...

foi vantajosa não apenas pelas relações comerciais que firmava, como pela marca social de ter um parente Familiar - ponto que poderia facilitar o processo de habilitação de João.

Vindo de Portugal, ouvindo o chamado do irmão mais velho, chegou a Recife Bernardo Pinto Martins; que se casou em terras pernambucanas no ano de 1771. O matrimônio foi com Ana Josefa, irmã da esposa de João Pinto Martins. Os dois irmãos casaram-se com duas irmãs e passaram a pertencer a uma mesma família no Brasil e a usufruir de capitais simbólicos e pecuniários associados a essa família. E mais, o casamento de Bernardo foi pouco comum para a época, pois tinha ele na ocasião mais ou menos trinta anos e sua esposa trinta e oito anos de idade. Josefa casou-se, para os padrões da época, numa idade bastante avançada, e Bernardo com uma mulher mais velha; situações raras no período.

Os irmãos continuaram juntos e continuaram a negociar junto. Nos Livros sobre as Receitas e Despesas da Provedoria do Siará Grande, encontramos mais dados sobre João e Bernardo. Em 1783, João Pinto Martins aparece como capitão-mor e Bernardo como sargento-mor. ${ }^{18}$ A nomeação para patentes militares era outra forma de valorização social, colocando seus detentores no rol dos bomens bons da região. ${ }^{19}$ Até 1783 , os irmãos se destacam por trilharem pari passu um franco processo de ascensão social: eram Familiares, tinham patentes militares, propriedades no Aracati, incluindo gados, contratos reais em Russas etc.

Mas, no triênio que finda em 1791, seus bens começaram a ser arrematados. Vendem o contrato de dízimo real em Russas para André Ribeiro. No mesmo período, têm outros contratos reais sequestrados pelas autoridades fiscais. Em 1788, os bois e cavalos que tinham na Ilha dos Veados, no rio Jaguaribe, foram sequestrados e arrematados. ${ }^{20}$

Em 1787, os irmãos, João e Bernardo, aparecem como defuntos. Segundo as memórias de um vereador de Aracati, Bernardo é assassinado do seguinte modo:

Entre os comersiantes desta Villa [Aracati] que para ella comersiavam tanto com fazendas como com a fabrica de carnes se dinumerava o Capitam João Pinto Martins e seu 
irmão Bernardo Pinto Martins os quaes para a fabrica das carnes tinham bastante escravos e entre ella hum preto de nome Francisco o qual hera cazado e porque huma noite tivera siumes de sua mulher... e com duas facadas a matara a cujas vozes acudira o senhor do mesmo Bernardo Pinto em quem o dito negro cravara a faca de que passando alguns dias morreu... (Registro da Mimória dos Novos Estabelessimentos Factos e Cazos Raros Acontessidos nesta Villa de Santa Cruz do Aracati feita Segundo a Ordem de sua Magestade e de 27 de Julho de 1782 pello Veriador Manoel Esteves de Almeida desde a Fundação da dita Villa the o Anno Prezente de 1795, apud NOBRE, 1977, p. 97).

Embora o depoimento trate apenas do assassinato de Bernardo, no ano seguinte, os dois irmãos aparecem como defuntos. O processo de perda das propriedades e contratos reais não pode ser considerado apenas como a decadência econômica desses Pinto Martins; mas provavelmente indique que, após suas mortes, a família das esposas tenha decidido encerrar os negócios no Ceará. De qualquer maneira, entre casamentos, aquisição de propriedades, comércio, habilitação do Santo Ofício, patentes etc., podemos entrever uma trajetória estrategicamente montada para o fortalecimento e ascensão social de João e Bernardo, que mantiveram uma aliança de cooperação e fortalecimento mútuo até a morte.

Se, por um lado, João e Bernardo agiram em sintonia; por outro, encontramos José Pinto Martins e seu irmão Antonio também articulando uma estratégia conjunta. Residiam entre Recife, Aracati e Mossoró. Diferentemente dos outros dois irmãos, não se casaram. Segundo registros, José morreu solteiro, em 1824. Os dois partiram do Ceará e foram fincar residência no Rio Grande do Sul. Apesar de alguns historiadores afirmarem que José chegou a Pelotas nos anos 80 do século XVIII, sua habilitação o aponta como morador do Ceará e de Pernambuco ainda em 1787 - o mesmo se aplicava para seu irmão. Provavelmente a partida dos irmãos da capitania do Ceará tenha acontecido nos anos 90 do século XVIII. O que se explica, em parte, pelas implicações 
De família, charque e Inquisição se fez a trajetória...

econômicas da Seca-Grande (1791-1793): redução de parcela significativa do rebanho cearense, desorganização de rotas comerciais, concentração em Aracati de retirantes que migravam do Sertão em busca de alimentos que chegavam pelo porto da vila, além das epidemias de varíola. $\mathrm{Na}$ mesma época, parte do patrimônio dos Pinto Martins foi a leilão, por ocasião da morte de João e Bernardo - marca de uma possível decadência nas propriedades dos Pinto Martins no Ceará.

A partida de José e Antonio para o arroio de Pelotas foi uma estratégia interessante, por envolver o deslocamento dos irmãos e de parte de suas propriedades entre dois extremos da América portuguesa. E, mesmo considerando as dificuldades de navegação, José Pinto Martins mantinha um brigue, chamado Conde da Figueira, que comercializava diretamente com Pernambuco (incluindo Aracati e Mossoró): o sal era a base do comércio e os contatos de Antonio em Mossoró podem ter rendido a continuidade desse comércio. Ou seja, José e Antonio não só partiram do Ceará para o Rio Grande do Sul, como estabeleceram uma rota comercial entre extremos da América lusitana. Com o passar dos anos, a empreitada comercial deu prejuízo, deixando uma dívida significativa no patrimônio de José Pinto Martins. ${ }^{21}$

Assim, José e Antonio vieram para o Brasil juntos, chamados por João. Aqui fizeram fortuna com o comércio, principalmente entre Aracati, Recife e Mossoró. A riqueza trouxe a possibilidade de ascensão social, e os dois, mais uma vez juntos, habilitaram-se como Familiares do Santo Ofício. Em fins dos anos 80 ou no começo dos anos 90 do século XVIII, partiram, também juntos, para o Rio Grande do Sul. Juntos, optaram por não se casar, diferentemente dos irmãos João e Bernardo. Em Pelotas, fincaram a base de suas atividades pecuaristas e comerciais. No testamento de José, lavrado em 1824, o irmão Antonio aparecia como beneficiado em 400\$000. José deixava claro que Antonio, o irmão, ainda vivia em sua companhia. Segundo as testemunhas das habilitações, José e Antonio haviam partido muito jovens de Meixomil, em Portugal, rumo a Pernambuco; e ainda no leito de morte, José se lembrava do irmão. 


\section{As Trajetórias}

As trajetórias dos Pinto Martins são instigantes para imaginarmos ações orquestradas entre os quatro irmãos; que se dividiram em duplas para fincarem riquezas e status em diferentes capitanias no Brasil. De netos de lavradores e filhos de jornaleiros, transformaram-se em ricos comerciantes, proprietários de charqueadas e barcos, além de entrarem para o rol seleto de Familiares do Santo Ofício. Aliás, a habilitação dos irmãos pode ser considerada como a marca do novo patamar social que atingiram nesse lado do Atlântico, patamar este que envolvia o acúmulo de bens e o atestado de limpeza de sangue. Mesmo assim, temos que considerar a relativa fortuna produzida pelos Pinto Martins, que talvez não se inserissem no grupo de comerciantes de Grosso Trato, com variedade de atividades comerciais e com inserção em redes clientelares que envolviam a metrópole e outras colônias, e nem mesmo tinham uma rede de conexões intercoloniais (FRAGOSO, 1998).

Tal fortuna se resumiu à geração dos primeiros Pinto Martins no Brasil e, já nos anos finais do século XVIII, apresentava uma fragmentação. Por ocasião da morte de Bernardo Pinto Martins, em fins da década de 1780, assistimos à venda de parte de seu patrimônio e dos bens de seu irmão João (também falecido na ocasião), incluindo direitos de fisco e terras, através de leilões promovidos pela Provedoria da Fazenda Real da Capitania do Ceará. ${ }^{22}$ Ao mesmo tempo, presenciamos a migração de José e Antonio para o Rio Grande do Sul e a confirmação de um considerável e lucrativo complexo do charque nessa região meridional. Por ocasião da morte de José Pinto Martins, em Pelotas, no ano de 1824, sua herança é dividida entre três filhos ilegítimos (filhos de escravas) e seu irmão, Antonio Pinto Martins.

Os Pinto Martins construíram riqueza em capitanias, com exceção de Recife, que estavam circunscritas a atividades com menor circulação de capital: pelo menos quando comparadas com a produção mineradora ou com o comércio de escravos. Embora não revelem ou se articulem diretamente com um mercado imperial 
ultramarino (FRAGOSO, et al., 2001), fortalecem-se como membros de uma elite local; infiltrando-se em engrenagens que consolidavam distinções sociais e referendavam grupos locais de controle político e econômico. Apesar disso, não podem ser incluídos no rol dos comerciantes que fizeram fortunas com empreendimentos nos vários mares onde os portugueses, em diferentes graus, estavam presentes (FRAGOSO, et al., 2001, p. 326). ra em quarteto, ora em dupla, ora individualmente, montaram uma competente rede comercial e de favorecimento pessoal que enredava fundamentalmente um comércio interno entre capitanias do norte e do sul do Brasil.

Os Pinto Martins utilizaram estratégias de enriquecimento nas quais a circulação de mercadorias era fundamental. De Recife, os barcos partiam abarrotados de produtos diversos vindos do Reino, como tecidos, machados, vinho, azeite etc. Na documentação pesquisada, não encontramos nenhum dos irmãos negociando diretamente com Lisboa, o que não significa que os produtos lisboetas não fossem adquiridos na capital pernambucana principalmente quando considerado o contrabando. ${ }^{23} \mathrm{E}$ era Recife o marco zero da trajetória dos Pinto Martins no Brasil, pois foi lá que desembarcaram quando vieram de Portugal, onde o irmão mais velho, João, arranjou casamento para ele e para o irmão, Bernardo, onde a família das esposas estava fixada, onde todos os quatro irmãos declararam residir e, principalmente, Recife era o centro administrativo e econômico da capitania de Pernambuco e de suas anexas (Ceará e Rio Grande do Norte).

Já Aracati era a vila mais rica da capitania do Ceará, marcada como ponto de partida de couro, sola e charque: feitos a partir de rebanhos que vinham do Sertão do Ceará, ou de capitanias vizinhas como do Rio Grande do Norte. Os produtos das oficinas de carne rumavam para Recife e de lá eram revendidos para diversas regiões. Por sua vez, produtos oriundos de Pernambuco eram despachados para o interior da capitania do Ceará através da venda em lojas dispostas nas principais e mais ricas ruas da vila. Nesse importante entreposto comercial, que servia como ponto de convergência de produtos do Sertão e de Recife, João Pinto Martins tinha oficina; era proprietário de um barco, dono de uma das mais importantes lojas da vila, possuía terras, contratos reais e 
rebanho na região de Aracati e Russas. Aliás, parte de sua propriedade era dividida com seu irmão, Bernardo, que era oficial da Câmara da vila, detinha a patente de sargento-mor (seu irmão João era capitão) e fora figura ativa na separação de Aracati da freguesia de Russas (1780).

Assú e Mossoró eram produtores de sal, matéria-prima da charqueada comercializada em Aracati (OLIVEIRA, 2006, p. 0708). Em 1788, o Capitão General de Pernambuco, D. Tomás José de Mello, obrigou que todas as oficinas potiguares fossem fechadas. O que ampliou a importância do charque produzido no Ceará. Antonio Pinto Martins morou em Mossoró, vila que deixava de concorrer com Aracati na produção de charque e, ao mesmo tempo, fornecia o sal e o gado.

Com a ida de Antonio e de José Pinto Martins para o Rio Grande do Sul, foi fortalecida a região como produtora de charque e potencial consumidora de sal. José Pinto Martins ainda hoje figura no rol de destacados nomes do Rio Grande do Sul, o que talvez se justifique por sua importância na produção em larga escala de charque em Pelotas. Com a presença de José e Antonio Pinto Martins no arroio, uma rota envolvia o transporte do sal oriundo de Mossoró: não nos esqueçamos de que José tinha uma embarcação que fazia com regularidade viagens entre o Sul e a capitania de Pernambuco, e que Antonio havia residido e explorado o comércio do sal potiguar. Proprietários de barcos, os Pinto Martins procuravam navegar sempre com produtos, criando uma rede comercial fundada no charque e no apoio familiar.

Em parte, fizeram da família a base para a inserção numa elite supracapitanias da América lusitana, do século XVIII. No entanto, tinham suas especificidades em relação às características desse grupo: primeiro, não pertenciam ao eixo minerador do Centro-Sul, área utilizada para se definir a formação dessa elite; segundo, embora tenham se valido de casamentos (João e Bernardo) como forma de consolidação de capital político e econômico, esse emaranhado familiar foi reduzido a dois irmãos e não se ampliou para outras gerações; terceiro, articulavam produção e comércio, mas não uma produção mineradora, e sim a produção pecuarista, 
De família, charque e Inquisição se fez a trajetória...

incluindo o criatório, e um comércio local (com lógeas); e por último, não se constituíam como uma nobreza da terra, apesar da habilitação e das patentes que detinham, e sim como uma elite essencialmente baseada no comércio e na produção de charque e couro, e não no latifúndio (FRAGOSO, 2005, p. 165-166).

Ainda segundo Fragoso, ${ }^{24}$ a economia colonial, ao longo do século XVIII, adquiriu maior complexidade, envolvendo diversas áreas produtoras, unidas por rotas comerciais de longa distância. Em parte, a trajetória de José Pinto Martins e dos seus irmãos confirma essa assertiva. Mas, ao mesmo tempo, insiste em lembrar que a América lusitana era bem mais que a exploração de ouro e diamantes no século XVIII. Áreas aparentemente alijadas das principais atividades econômicas da Coroa poderiam não apenas produzir capital, como se relacionarem à lógica de poder baseada em capitais simbólicos e em lucros comerciais; muitas vezes, legitimadas por instituições como o Santo Ofício.

José Pinto Martins mudou de status no Brasil. De filho de jornaleiro de Meixomil se transformou em proprietário de um rico patrimônio no Rio Grande Sul. O que mais se destaca em sua história não é o começo, nem o fim, mas o meio pelo qual fez fortuna e ganhou a bênção do Santo Ofício. Ganhou destaque social através do comércio, comprando, vendendo e lucrando entre vilas diferentes no Brasil. Nada de grandes e mirabolantes rotas transatlânticas, nada de possessões na África ou representantes em Lisboa. Os Pinto Martins ganharam dinheiro e status no Sertão da pecuária, comercializando diretamente com capitanias dos extremos da América lusitana. O que não impede que a produção de capital, o lucro originado a partir de grandes rotas comerciais, não tenha facilitado o desenvolvimento de suas atividades comerciais. ${ }^{25}$ Mas, fundamentalmente, José e seus irmãos se apoiaram mutuamente, articularam estratégias e aproveitaram as oportunidades.

Assim, na trajetória de José Pinto Martin, vislumbramos mais uma possibilidade de se fazer fortuna no Brasil e de se conseguir mobilidade social, o que muitas vezes foi ignorado por teorias explicativas, circunscritas à parte da América. Quando José morreu, nasceram novas possibilidades de conhecermos parte do 
passado colonial, um passado que também tem o Sertão do Ceará, as salinas potiguares e os arroios de Pelotas como fontes de riqueza e ascensão social.

\section{Family, charque and Inquisition was the trajectory of the Pinto Martins (1749-1824)}

Abstract: This paper presents the strategies adopted by four brothers who went to Portugal and made fortune in Brazil. The Pinto Martins, children of a digger of wells, built primarily from the wealth and trade Charqueadas, is worth a distribution involving the captaincy of Pernambuco, Rio Grande do Norte, Ceará and Rio Grande do Sul Throughout second half of the eighteenth century and the first decades of the nineteenth, the brothers drew up a history of enrichment based on relations of kinship, the alliances and mutual commitments. The family was based on support for them to be effective as good men, military holders of patents, contracts and real lay members of the Inquisition.

Keywords: Charqueadas. Inquisition. Ceará. Rio Grande do Sul. Elite.

\section{Notas}

${ }^{1}$ A história das elites trata de conhecer as propriedades sociais mais requisitadas em cada grupo, sua valorizasão através do tempo; conhecer a composição dos capitais ou atributos cultural, econômico ou social, e sua inscrição nas trajetórias dos indivíduos... (Cf. HEINZ, 2006, p. 09).

${ }^{2}$ Arquivo Público do Rio Grande do Sul, Testamento n. 1607, Maço 85, Est. 06, Pelotas $-1{ }^{\circ}$ Cartório Orphãos e Provedoria.

${ }^{3}$ Arquivo Público do Rio Grande do Sul, Testamento n. 1607, Maço 85, Est. 06, Pelotas $-1{ }^{\circ}$ Cartório Orphãos e Provedoria.

${ }^{4}$ Os ossos eram fervidos até a extração do tutano, para fabricação de manteiga.

${ }^{5}$ Estima-se que, durante a exploração do ouro no Brasil, a taxa de emigração de Portugal chegou a 4.0 por mil. A região norte de Portugal foi destacadamente a área de maior emigração para o Brasil ao longo do século XVIII (SCOTT, 1999, p. 35-6). ${ }^{6}$ Idem, p. 53.

${ }^{7}$ Cf. http://www.jf-freamunde.pt/historia.html., acessado em 20 de março de 2009.

${ }^{8}$ Toda a trajetória da família Pinto Martins em Portugal foi construída através da habilitação do irmão mais velho de José, João Pinto Martins. DGARQ/IANTT, Habilitação de Familiares, maço. 157, doc. 1267. 
${ }^{9}$ DGARQ/TT, Habilitação de Familiares, maço 157, doc. 3031

${ }^{10} \mathrm{O}$ detalhamento do fluxo de capital e a intensidade do comércio que envolvia o charque em Aracati pode ser encontrado em OLIVEIRA, 2006 ou em RIBEIRO Jr., 1976.

${ }^{11}$ DGARQ/TT, Habilitação de Familiares, maço. 157, doc. 1267.

${ }^{12}$ Regimento do Santo Ofício da Inquisição dos Reinos de Portugal, ordenado pelo Cardeal Da Cunha, 1774. Título IX: dos familiares do Santo Ofício."

${ }^{13}$ Regimento do Santo Oficio da Inquisição dos Reinos de Portugal, ordenado pelo Cardeal Da Cunha, 1774. Título IX: dos familiares do Santo Ofício.

${ }^{14}$ Lógea: loja em construção não assobradada. Socialmente está em patamar inferior às lojas em sobrados.

${ }^{15}$ Instituto Histórico do Ceará. Ata da Reunião da Câmara de Aracati, 1746. Livro III, 1684-1762, Coleção Studart.

${ }^{16}$ DGARQ/TT, Habilitação do Santo Ofício, maço. 157 , proc. 1267.

${ }^{17}$ Existe um extenso debate acerca da possibilidade de implementação de uma sociedade com base no Antigo Regime aqui nos trópicos. A base da crítica é a minimização do poder do Estado e o abandono da problemática da escravidão (SOUZA, 2006, p. 58). Mas esse debate fica circunscrito às capitanias do Centro-Sul, sem considerar as especificidades de capitanias do Norte.

${ }^{18}$ DGARQ/TT, Papéis do Brasil, Livro 212.

${ }^{19}$ DGARQ/TT, Papéis do Brasil, Livro 216.

${ }^{20}$ DGARQ/TT, Papéis do Brasil, Livro 217.

${ }^{21}$ Arquivo Público do Rio Grande do Sul, Testamento No 1607, Maço 85,Est. 06, Pelotas $-1^{\circ}$ Cartório Orphãos e Provedoria.

${ }^{22}$ DGARQ/TT, Papéis do Brasil, Livro 232. He da importância da metade da arrematação que fez de 182 Bois de asogue a 3:300 rs cada hum da fazenda a More, cita na Ribeira de Jaguaribe sequetrada ao Cazal de defunto João Pinto Martins e seu irmão e sócio Bernardo Pinto Martins, contratadores que forao dos Dízimos Reais da Freguesia de Russas... [1789] Jose Antonio de Almeida.

${ }^{23}$ Arquivo Histórico Ultramarino de Portugal [Projeto Resgate], Documentos Avulsos da Capitania de Pernambuco, doc. 8493. Documento que apresenta interessante caso de contrabando, em 1770, que envolvia a capitania do Ceará. O rol de produtos e suas origens surpreendem pela variedade de origens.

${ }^{24}$ FRAGOSO, 2005, p.165.

${ }^{25}$ Embora exista referência à utilização do charque na aquisição de escravos na África, não encontramos nenhuma notícia na documentação pesquisada da participação dos Pinto Martins nesse comércio. 


\section{Referências Bibliográficas}

ARAÚJO, Emanuel. Tão Vasto, Tão Ermo, Tão Longe: o Sertão e o Sertanejo nos Tempos coloniais. In: DEL PRIORE, Mary (Org.). Revisão do Paraíso. Rio de Janeiro: Campus, 2000, p.45-92.

ASSUNÇÃO, Paulo e FRANCO, José Eduardo. As Metamorfoses de um Polvo. Lisboa: Prefácio Editora, 2004.

BETHENCOURT, Francisco. História das Inquisições. Lisboa: Circulo de Leitores, 1994.

CALAINHO, Daniela. Em Nome do Santo Ofício. Rio de Janeiro: Universidade Federal do Rio de Janeiro, dissertação de mestrado em História, 1992, 192 p.

CALAINHO, Daniela. Agentes da Fé. Bauru, SP: EDUSC, 2006 a.

CALAINHO, Daniela. Pelo Reto Mistério do Santo Ofício: falsos agentes inquisitoriais no Brasil colonial. In: VAINFAS, Ronaldo; FEITLER, Bruno e LAGE, Lana. A Inquisição em Xeque. Rio de Janeiro: Ed. UERJ, FAPERJ, 2006b, p. 87-96.

CROSSETTI, Vanda. O Escravismo no Rio Grande do Sul - século XIX. In: QUEVEDO, Júlio (Org.). Rio Grande do Sul 4 séculos de História. Porto Alegre: Martins Livreiro, 1999.

FRAGOSO, João. Homens de Grossa Aventura. Rio de Janeiro: Civilização Brasileira, 1998. 2001.

et al. O Antigo Regime nos Trópicos. Rio de Janeiro: Civilização Brasileira,

Potentados coloniais e circuitos imperiais: notas sobre uma nobreza da terra, supracapitanias, nos setecentos. In: MONTEIRO, Nuno et al. Optima Pars. Lisboa: ICS, 2005, p. 133-68.

et. al. Nas Rotas do Império. Vitória: Edufes, Lisboa: IICT, 2006.

GUTIERREZ, Ester. Negros, Charqueadas \& Olarias. Pontifícia Universidade Católica do Rio Grande do Sul, dissertação em História, 1993, 281p.

HEINZ, Flávio (Org.). Por outra história das elites. Rio de Janeiro: FGV, 2006.

HIGGS, David. Comissários e Familiares da Inquisição no Brasil aos Fim do Período Colonial. In: NOVINSK, Anita e CARNEIRO, Maria Luiza Tucci. Inquisição: Ensaios sobre Mentalidade, Heresias e Arte. São Paulo: Edusp, 1992, p. 374-407.

MELLO, Evaldo Cabral de. O Nome e o Sangue. Rio de Janeiro: TopBooks, 2000. 
De família, charque e Inquisição se fez a trajetória...

MONTEIRO, Nuno. Elites e Poder. Lisboa: ICS, 2003.

NOBRE, Geraldo. As Oficinas de Carne do Ceará. Fortaleza: Gráfica Editorial Cearnse, 1977.

OLIVEIRA, Almir Leal. A Dimensão Atlântica da Empresa do Charque: o Ceará e as dinâmicas do mercado colonial (1767-1783). In: Anais Eletrônicos do I Encontro Nordestino de História Colonial, João Pessoa, UFPB, 2006.

RIBEIRO Jr., José. Colonização e Monopólio no Nordeste Brasileiro. São Paulo, HUCITEC, 1976.

SCOTT, Ana Silvia Volpi. Familias, Formas de União e Reproducão Social no Noroeste Português (séculos XVIII e XIX). Guimarães: NEPS/Univ. do Minho, 1999.

SIQUEIRA, Sonia. A Inquisição Portuguesa e a Sociedade Colonial. São Paulo: Ed. Ática, 1978.

SOUZA, Laura de Mello. O Sole a Sombra. São Paulo: Cia. das Letras, 2006.

TORRES, José Veiga. Da Repressão Religiosa para a Promoção Social: a Inquisição como instância legitimadora da promoção social da burguesia. Revista de Ciências Sociais, Lisboa, n. 40, 1994, p. 109-135.

WADSWORTH, James. In The Name Of The Inquisition:The Portuguese Inquisition And Delegated Authority In Colonial Pernambuco, Brazil. In: The Americas: v. 61, n.1, July, 2004, p. 19-54.

VAINFAS, Ronaldo (Org.). Dicionário do Brasil Colonial. Rio de Janeiro: Objetiva, 2000.

VIEIRA Jr., Antonio Otaviano. Entre Paredes e Bacamartes: história da família no Sertão (1780-1850). Fortaleza: Fund. Demócrito Rocha, São Paulo: HUCITEC, 2004. . A Inquisição o Sertão. Fortaleza: Fund. Demócrito Rocha, 2008. 